\title{
Marketing sustentável para a melhoria da gestão de resíduos sólidos urbanos em município do Alto Uruguai Gaúcho, Estado do Rio Grande do Sul, Brasil
}

\author{
Silvana Saionara Gollo' ${ }^{1}$, Keila Cristina da Rosa ${ }^{1}$, Angelita Freitas \\ da Silva ${ }^{1}$, Cassiana Bortoli ${ }^{1}$, , Adriana Troczinski Storti ${ }^{2}$ e Marcio \\ Rogério Silva Carvalho ${ }^{2}$
}

\footnotetext{
${ }^{1}$ Instituto Federal de Educação, Ciência e Tecnologia do Rio Grande do Sul. Campus Erechim. Rua Domingos Zanella, 104. Três Vendas. Erechim-RS, Brasil (CEP 99713028). E-mail: cassianabortoli@gmail.com.

${ }^{2}$ Programa de Pós-Graduação e Inovação. Instituto Federal de Educação, Ciência e Tecnologia do Rio Grande do Sul. Campus Erechim. Rua Domingos Zanella, 104. Três Vendas. Erechim-RS, Brasil (CEP 99713-028).

${ }^{3}$ Rogopar Comércio de Parafusos. Rua Silveira Martins, 352. Centro. Erechim-RS, Brasil (CEP 99700-092).
}

Resumo. Resíduos sólidos urbanos secos são aqueles que podem ser reciclados gerando emprego e renda em associações de recicladores. Apesar de haver dispositivos legais sobre o tema, muitos problemas são enfrentados em relação à sua gestão. Diante deste contexto, o presente artigo tem como objetivo analisar o procedimento de descarte e destinação dos resíduos sólidos urbanos no Município de Erechim, localizado no Alto Uruguai Gaúcho, Estado do Rio Grande do Sul, Brasil, buscando propor estratégias de marketing que possam contribuir para a melhoria de sua gestão. Os dados foram coletados através de entrevistas e levantamento do tipo survey. Na etapa qualitativa destacam-se os principais problemas enfrentados pelas associações de recicladores, como a falta de conscientização da população quanto à separação e destino do lixo, condições de trabalho precárias, falta de segurança, infraestrutura e a discriminação da profissão. Na etapa quantitativa destaca-se a confirmação do desconhecimento da população a respeito da gestão dos resíduos sólidos urbanos. Quase a totalidade dos entrevistados afirmou realizar a separação dos resíduos secos e orgânicos, porém, mais da metade tem dúvidas na sua diferenciação. Ao solicitar-se a classificação de resíduos secos e orgânicos de uma lista apresentada, boa parte não soube identificar corretamente. Na concepção de que a gestão dos resíduos sólidos urbanos está ligada ao marketing sustentável, propõe-se estratégias com foco no tripé social, ambiental e econômico. Como implicações gerenciais oportunizadas por esta pesquisa, destaca-se a possibilidade das ações propostas melhorarem a atuação dos recicladores dentro das associações.
Recebido:

$14 / 02 / 2019$

Aceito:

19/04/2019

Publicado:

30/04/2019

Acesso aberto

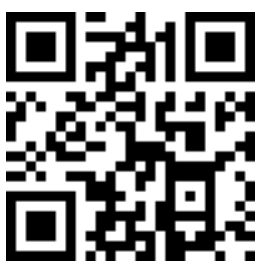

ORCID

(ㄱ) 0000-0002-2229-1510 Silvana Saionara Gollo

(1) 0000-0003-4557-6372 Keila Cristina da Rosa

(D) 0000-0002-1046-4795 Angelita Freitas da Silva 
Palavras-chave: Marketing sustentável; Estratégias de marketing sustentável; Resíduos sólidos urbanos.

\begin{abstract}
Sustainable marketing for improving the management of solid urban waste in municipality of High Uruguay Gaúcho, Rio Grande do Sul State, Brazil. Dry solid urban wastes are those that can be recycled generating jobs and income in waste picker associations. Although there are legal provisions on the subject, many problems are faced in relation to its management. In this context, the objective of this article is to analyze the procedure for disposal and disposal of solid urban waste in the Municipality of Erechim, located in Alto Uruguai Gaúcho, State of Rio Grande do Sul, Brazil, seeking to propose marketing strategies that may contribute to management. Data were collected through interviews and surveys. At the qualitative stage, the main problems faced by recyclers' associations are the lack of awareness of the population regarding the separation and destination of garbage, poor working conditions, lack of safety, infrastructure and discrimination of the profession. In the quantitative stage, the confirmation of the population's lack of knowledge about solid urban waste management is highlighted. Almost all of the interviewees claimed to carry out the separation of dry and organic waste, but more than half have doubts about their differentiation. When requesting the classification of dry and organic waste from a list presented, much of it could not identify correctly. In the conception that solid urban waste management is linked to sustainable marketing, strategies are proposed with a focus on the social, environmental and economic tripod. As managerial implications opportunized by this research, it stands out the possibility of the proposed actions to improve the performance of the recyclers within the associations.
\end{abstract}

Keywords: Sustainable marketing; Sustainable marketing strategies; Urban solid waste.

\section{Introdução}

0 aumento populacional, a rápida urbanização, a economia em expansão e o aumento do padrão de vida nos países em desenvolvimento, têm gerado maior consumo de produtos e serviços. Muitas vezes de forma não sustentável, contribuindo para o aumento da quantidade e a qualidade da geração de resíduos sólidos urbanos (Hussein e Mona, 2018; Queiroz e Vieira, 2018). Godecke et al. (2012) em seu estudo, relacionam a questão demográfica com aspectos econômicos e culturais, associando a quantidade de resíduos sólidos urbanos produzida aos níveis de
๑ 0000-0003-1307-2110

Cassiana Bortoli

D) 0000-0001-6601-6943

Adriana Troczinski Storti

D $0000-0002-3227-8301$

Marcio Rogério Silva

Carvalho 
gestores públicos preocupados em tornar as cidades mais inteligentes $\mathrm{e}$ sustentáveis (Rodrigues et al., 2018), visto que tem influência direta sobre a qualidade ambiental e social das cidades, e, portanto, para o desenvolvimento sustentável (Peltola et al., 2016).

Apesar de sua importância estratégica, a gestão dos resíduos sólidos urbanos não tem acompanhado eficientemente a evolução das tecnologias de produção limpa, em busca de resultados sustentáveis. Razão pela qual, tem causado impactos socioambientais negativos, como: a degradação do solo, o comprometimento dos corpos d'água e mananciais, a intensificação de enchentes, a poluição do ar e proliferação de vetores de importância sanitária nos centros urbanos, o aquecimento global, as mudanças climáticas, e, ainda, a catação em condições insalubres nas ruas e nas áreas de disposição final (Jacobi e Besen, 2011), o que geram problemas de saúde pública. 0 aumento da geração de resíduos sólidos em cidades urbanas afetou drasticamente os problemas sanitários e os serviços básicos, como instalações de saneamento, abastecimento de água, gestão de resíduos e infraestrutura de transporte (Liyala, 2011).

Assim, uma orientação estratégica deve ser dada à gestão de resíduos sólidos urbanos, uma vez que, se integrada a eficiência de recursos, segurança, políticas sociais, ambientais e de saúde pública, serve de referência às operações, processos e oferta de serviços sustentáveis dos municípios (Li et al., 2015). Diante da necessidade de tratar o tema de forma estratégica, a sociedade vem debatendo alternativas para solucionar problemas relacionados à gestão dos resíduos sólidos urbanos, envolvendo a incorporação de tecnologias, a mudança de processos produtivos e a legislação.

No Brasil, algumas iniciativas legais à gestão dos resíduos sólidos urbanos estão institucionalizadas, como a Política Nacional de Resíduos Sólidos Urbanos, os Planos Estaduais de Resíduos Sólidos e os Planos de Resíduos Sólidos Urbanos em nível municipal. Apesar de haver disposições legais sobre o tema, muitos problemas ainda são enfrentados, desde seu fluxo inicial até seu destino final, seja no aterro sanitário (resíduos orgânicos) ou nos processos de reciclagem em associações de recicladores (resíduos sólidos). No país, há o reconhecimento de um importante segmento da sociedade, relativo aos resíduos sólidos urbanos, que são as associações de catadores de materiais recicláveis e reutilizáveis, ou simplesmente, recicladores. A relevância desse segmento econômico e a sua crescente força política permitiu o seu reconhecimento, pela Política Nacional de Resíduos Sólidos do Brasil (Lei no 12.305/2010) (Brasil, 2010), e da própria Lei Nacional de Licitações e Contratos (Lei no 8.666/1993) (Brasil, 1993), através de cláusula inserida em 2007, que permite a contratação direta de cooperativas e associações de recicladores de materiais recicláveis pela administração pública, notadamente pelos governos locais.

Uma vez gerados, os resíduos sólidos não deixam, necessariamente, de possuir valor. Assim, uma das medidas possíveis de serem tomadas para a redução de problemas ligados à gestão de resíduos sólidos urbanos é a reciclagem, visto que parte significativa de materiais pode ser reutilizada, recuperada ou reutilizada, de forma a reintegrá-los ao ciclo econômico, contribuindo para a economia de recursos e gerando emprego e renda à população (Bartholomeu e Caixeta-Filho, 2011).

Diante deste contexto, o presente artigo tem como objetivo analisar os procedimentos de separação, descarte e destinação dos resíduos sólidos urbanos secos no Município de Erechim, no Alto Uruguai Gaúcho, assim como, propor estratégias de marketing que possam contribuir para melhoria da gestão destes resíduos. Apesar da importância 
de se estudar sistemicamente os resíduos sólidos urbanos, optou-se neste artigo, como forma de delimitar o tema, pelo estudo dos resíduos sólidos urbanos secos. Neste sentido, a questão que deu norte à pesquisa é: quais são as estratégias de marketing sustentável que podem contribuir para a melhoria da gestão dos resíduos sólidos urbanos secos de um Município de Erechim, do Alto Uruguai Gaúcho.

No Município de Erechim, existem seis associações de recicladores que trabalham com resíduos sólidos urbanos, cinco delas com resíduos secos, e uma com resíduos orgânicos, essa situada no aterro sanitário. 0 município também possui um Plano de Resíduos Sólidos Urbanos, que dispõe sobre a universalização dos serviços de coleta dos resíduos domiciliares, a redução e geração per capita dos resíduos domiciliares, a qualidade da coleta dos resíduos domiciliares, a sustentabilidade econômica e financeira, e a destinação final ambientalmente adequada. Entretanto, neste município existem problemas relacionados à coleta, separação, descarte e destinação de resíduos sólidos urbanos, cujas causas podem estar ligadas à falta de conscientização e de informações da população sobre o manejo correto dos resíduos gerados nos domicílios e em empresas industriais, comerciais e prestadoras de serviços.

\section{Marketing sustentável}

0 marketing e a sustentabilidade parecem ser conceitos incompatíveis, visto que esta é atingível através da redução do consumo ou do consumo consciente e sustentável, enquanto àquele tem por objetivo o aumento do consumo. Entretanto, essa aparente diferença vem sendo gradativamente superada, visto que a sustentabilidade tem emergido como um novo paradigma do marketing (Kumar et al., 2012; Baldassarre e Campo, 2016). A Associação Americana de Marketing (AMA, 2013), redefiniu o conceito de marketing concedendo-lhe como uma atividade, conjunto de instituições e processos para criar, comunicar, entregar e trocar ofertas que tenham valor para os consumidores, clientes, parceiros e sociedade em geral. Nessa evolução, surge o conceito de marketing social, entendido como uma modalidade de ação mercadológica institucional que tem como objetivo principal atenuar ou eliminar os problemas sociais, as carências da sociedade relacionadas, principalmente, às questões de higiene e saúde pública, trabalho, educação, habitação, transportes e nutrição (Kotler et al., 2010).

Recentemente, o marketing sustentável surge como um novo conceito em marketing e negócios, que, com base no conceito de sustentabilidade, e nos pilares econômico, ambiental e social, busca satisfazer as necessidades desta geração de consumidores, sem prejudicar as gerações futuras. Assim, as organizações têm sido cobradas para que exerçam de forma efetiva sua responsabilidade no processo de sustentabilidade, assumindo valores e práticas sustentáveis, visto que não podem restringir-se a fornecer e comercializar produtos e serviços, mas precisam agregar valor econômico, social e ambiental às suas ações, a fim de superar as expectativas dos consumidores e inspirar confiança no mercado, tornando-se um agente de mudanças positivas na sociedade (Zenone e Dias, 2015; Pomering, 2017; Stumpf et al., 2018).

Neste contexto, o marketing sustentável configura-se como uma nova forma de compreender e praticar relações de troca com consumidores, fornecedores e demais stakeholders da organização, considerando o impacto das atividades produtivas na sociedade (Zenone e Dias, 2015). Os autores enfatizam que o papel fundamental do marketing sustentável é remover barreiras para gerar um consumo sustentável. No marketing sustentável há desenvolvimento e venda de produtos 
sustentáveis, bem como a geração de conhecimento, motivação e recursos para que o consumidor possa usar e eliminar o produto de forma sustentável. Neste enfoque, consumidor e empresa desenvolvem uma relação que cria valor para a sociedade, aplicando o triple bottom line (pilar social, ambiental $\mathrm{e}$ econômico) (Zenone e Dias, 2015).

\section{Estratégias de marketing sustentável}

As estratégias de marketing sustentável aplicam o conceito de sustentabilidade na esfera empresarial. Neste sentido, as estratégias de marketing passam a considerar a responsabilidade social e ambiental e o foco econômico no desenvolvimento do composto de marketing: produto, preço, comunicação e distribuição (Ambrósio, 2007; Gracioso, 2012; Zenone e Dias, 2015). Para Zenone (2007) e, ainda, Zenone e Dias (2015), a estratégia de comunicação sustentável permite chegar a novos segmentos caracterizados por serem mais respectivos aos princípios solidários da responsabilidade social e ambiental, de forma informativa e não persuasiva, conscientizando o consumidor sobre práticas de consumo consciente. Na estratégia de produto, há necessidade de analisar a composição destes, quanto as suas características intrínsecas e as fontes de origem da matéria-prima, bem como tudo que se relaciona ao processo de produção. Enfoca ainda as questões sociais, como condições de trabalho, segurança e cultura, além das questões ambientais, tanto dos resíduos diretos originados do próprio produto em si, como dos derivados da embalagem. A estratégia de preços deve ser considerada como um elemento de atuação que contribua para mudanças culturais, destinando um percentual das compras de determinado dia/produto a causa social e/ou ambiental (Enoki et al., 2008). Além disso, envolve o custo total social de uma prática irresponsável, não apenas para a empresa ou para o consumidor, mas à sociedade como um todo. A estratégia de distribuição envolve um conjunto de atividades necessárias que vão desde a saída do produto do processo produtivo até seu destino, que é o fornecedor, além das atividades de armazenamento, embalagens e transportes e a logística reversa.

\section{urbanos}

\section{Gestão de resíduos sólidos}

A crescente preocupação com o meio ambiente e com as questões relacionadas à saúde pública, em particular com a gestão dos resíduos sólidos, sinalizam que as políticas sociais com a finalidade de tratar deste tema tendem a ser cada vez mais demandadas. Não obstante, quando o assunto em debate diz respeito ao desenvolvimento de uma sociedade mais sustentável, necessariamente, exige-se maior sofisticação na gestão dos resíduos sólidos urbanos (Seadon, 2010). Os resíduos sólidos urbanos são os materiais originários das atividades humanas sejam elas industriais, comerciais, domiciliares, hospitalares, agrícolas que podem provocar efeitos prejudiciais ao homem, às instalações e ao meio ambiente (Assumpção, 2011).

O Plano Nacional de Resíduos Urbanos - PNRU (Brasil, 2011), instituído pela Lei no 12.305/2010 (Brasil, 2010), contém instrumentos importantes para permitir o avanço necessário ao país no enfrentamento dos principais problemas ambientais, sociais e econômicos decorrentes do manejo inadequado dos resíduos sólidos. Tal plano contempla a prevenção e a redução na geração de resíduos, tendo como proposta a prática de hábitos de consumo sustentável e um conjunto de instrumentos para propiciar o aumento da reciclagem e da reutilização dos resíduos sólidos (o que tem valor econômico e pode ser reciclado ou reaproveitado) e a destinação ambientalmente adequada dos rejeitos (o que não pode ser reciclado ou reutilizado). 0 plano prevê 0 gerenciamento de resíduos sólidos como 
o conjunto de ações exercidas, mesmo que indiretamente, na coleta, no transporte, no transbordo, no tratamento e na destinação final adequada dos resíduos, e na disposição final ambientalmente correta dos seus rejeitos, de acordo com o que estiver previsto no plano municipal de gestão integrada de resíduos sólidos e com os diversos planos de gerenciamento de resíduos sólidos (Erechim, 2017).

Dentre as disposições elencadas pelo PNRU (Brasil, 2011), os entes federados devem elaborar Planos de Gestão de Resíduos Sólidos (art. 8oㅜ em níveis nacional, estadual e regional, havendo expressa previsão da faculdade de elaboração de planos de regiões metropolitanas (art. 14, III), ou até, na forma de consórcios entre os entes federados (art. 8ㅜ, XIX). Para o sucesso do PNRU (Brasil, 2011), os referidos planos devem ser realizados, de preferência, na forma integrada, ou seja, busca-se a Gestão Integrada Dos Resíduos Sólidos (Brasil, 2014), que consiste no conjunto de ações voltadas para a busca de soluções para os resíduos sólidos, de forma a considerar as dimensões política, econômica, ambiental, cultural e social, com controle social e sob a premissa do desenvolvimento sustentável (art. 3ํ, XI).

Para além dos aspectos legais que envolvem as terminologias empregadas nestes planos (nacional, estadual, municipal), pode-se concluir que a gestão adequada dos resíduos sólidos envolve aspectos ligados à educação ambiental, à coleta seletiva, ao estímulo a comercialização de materiais recicláveis, compostagem, à inclusão de recicladores e à adoção de sistema ambientalmente adequado para a disposição final de rejeitos. Ainda, pode-se dizer que o sistema de resíduos sólidos é composto por diversas etapas e atores que, quando reunidos, proporcionam eficiência e harmonia às regras previstas pela Política Nacional de Resíduos Sólidos (Silva Filho e Soller, 2012), bem como pelos planos estaduais e municipais de gestão dos resíduos sólidos urbanos.
Segundo Machado (2015), quando da instituição do Plano Nacional de Resíduos Urbanos (Brasil, 2011) considerou-se o princípio da responsabilidade compartilhada, tornando obrigatório que todos os geradores de resíduos sólidos gerenciem seus resíduos da forma mais adequada.

No Brasil e no Município de Erechim, destaca-se a existência de recicladores, sendo que muitos deles trabalham de forma organizada, já possuem amparo legal e administrativo e estão estruturados em associações ou cooperativas com expressiva força política (Shaffer et al., 2010). Para Gouveia (2012), existem diferenças regionais no que se refere à produção de resíduos, mas tal produção é crescente em todas as regiões e estados brasileiros. Bartholomeu e Caixeta Filho (2011) enfatizam a importância da redução da geração de resíduos, resultante de um processo de conscientização da população.

\section{Material e métodos}

A pesquisa caracteriza-se, quanto à abordagem do tema, em qualitativa e quantitativa, e quanto aos objetivos, trata-se de uma pesquisa de natureza exploratória, conforme descrevem Malhotra (2012) e Shaffer et al (2010). Neste sentido, sua execução foi realizada em duas etapas.

A etapa qualitativa foi realizada utilizando-se o método do estudo de caso (Yin, 2015). Tendo como objetivo compreender melhor a realidade vivenciada pelas associações de recicladores de lixo de um município do Alto Uruguai Gaúcho, os principais problemas enfrentados por eles com relação à gestão dos resíduos sólidos urbanos daquele município, em especial quanto à coleta, separação e destinação dos mesmos. E, assim, obter o subsídio necessário para a proposição de estratégias de marketing sustentável que possam contribuir para a melhoria da 
gestão destes resíduos no município como um todo.

O Município de Erechim, conta com seis associações de recicladores, que trabalham com os resíduos urbanos gerados por seus mais de 100.000 habitantes. Destas, cinco associações são responsáveis pela coleta, separação e reciclagem do lixo seco e uma pelo lixo orgânico. Considerando a delimitação dada ao estudo, o objeto de pesquisa se restringiu às cinco primeiras associações (que trabalham com resíduos sólidos urbanos secos), sendo que destas, três aceitaram fazer parte da pesquisa.

Com relação aos sujeitos de pesquisa nesta primeira etapa, foram entrevistados 19 dos 43 colaboradores das associações. Também foi selecionada uma profissional do ramo (expert) com experiência e conhecimento na área para realização de uma entrevista em profundidade. A pessoa selecionada atua como assistente social e trabalha diretamente com as associações de recicladores do município.

Para a coleta dos dados foram utilizadas diferentes fontes de evidência, visando a triangulação de técnicas qualitativas: pesquisa documental, realização de entrevistas e observação, trabalhando-se com dados primários e secundários. As entrevistas com os recicladores e com a profissional da área foram gravadas, com prévia anuência, para facilitar a transcrição e interpretação dos dados obtidos, e seguiram roteiros semiestruturados. A etapa de observação possibilitou uma compreensão melhor acerca do ambiente pesquisado, uma vez que foram apresentadas as instalações das associações e o fluxo de trabalho envolvido, e também permitiu verificar e checar algumas informações mencionadas nas entrevistas, comparando o discurso dos entrevistados com a prática de fato adotada nas associações. Além dos dados primários, foram realizadas análises documentais abrangendo a consulta de livros e artigos científicos, e informações disponibilizadas em sites e em documentos oficiais (Plano Nacional de Resíduos Urbanos (Brasil, 2011), Plano Regional de Resíduos Sólidos do Rio Grande do Sul e Plano de Resíduos Sólidos Urbanos do município de estudo). Esta etapa da coleta possibilitou o esclarecimento de conceitos importantes relacionados à temática, informações iniciais a respeito do público a ser investigado e ainda orientou a elaboração do instrumento de pesquisa utilizado na etapa quantitativa. Por fim, os dados obtidos foram analisados qualitativamente, por meio de análise de discurso considerando-se os textos e falas dos entrevistados $\mathrm{e}$ as demais fontes de evidência.

A partir dos resultados da etapa qualitativa, percebeu-se que uma parcela significativa dos problemas relacionados à gestão dos resíduos sólidos urbanos do município pode ter relação direta com a forma com que os mesmos são descartados pela população. Neste sentido, a pesquisa contou com uma segunda etapa, de abordagem quantitativa, realizada apor meio de levantamento do tipo survey (Malhotra, 2012), com o intuito de verificar o nível de conhecimento da população do município sobre aspectos ligados à gestão dos resíduos sólidos urbanos, seus comportamentos em relação ao lixo gerado em suas residências, em especial à separação e destinação destes materiais, visando complementar as informações até então encontradas e dar maior subsídio para a proposição das estratégias. Para esta etapa, o instrumento de pesquisa utilizado foi um questionário estruturado composto por 23 questões fechadas dos tipos dicotômica e de múltipla escolha, e abertas, construído a partir dos resultados iniciais da etapa qualitativa, visando identificar o perfil dos respondentes, o nível de conhecimento sobre questões relacionadas a gestão dos resíduos sólidos urbanos e comportamentos adotados em relação a separação e descarte destes. 
Com relação ao universo da pesquisa, o mesmo corresponde à população total do município estudado, composta por 102.906 pessoas (IBGE, 2010). Com relação a amostra, utilizou-se a técnica de amostragem não probabilística por conveniência, calculada a partir da população total e com base nos seguintes parâmetros estatísticos, $\mathrm{Z}=$ número do desvio padrão $(1,96$ para intervalo $95 \%$ de confiança/margem de segurança); $\mathrm{p}=$ estimativa da proporção (50\%); $q=1-p$ (1 - estimativa da proporção), sendo ( $\mathrm{p}+$ q) $=100 \%$, então q $=50 \%$; e = erro amostral (desvio padrão da proporção, 5\%), resultando um total de 332 de pessoas. Ao final foram contabilizadas 333 respostas. Os dados foram analisados quantitativamente por meio de análise de frequência.

Após a coleta dos dados da pesquisa, realizou-se uma análise SWOT, com o intuito de destacar dentro dos resultados obtidos, pontos fortes e fracos, oportunidades e ameaças, os quais foram utilizados como subsídios à proposição das estratégias de marketing sustentável que contribuam para a melhoria da gestão dos resíduos sólidos urbanos secos no município em estudo.

\section{Resultados e discussão}

O Plano de Resíduos Sólidos Urbanos do Município em estudo e as Associações de recicladores

O Município possui um Plano de Resíduos Sólidos Urbanos que objetiva a universalização dos serviços de coleta dos resíduos domiciliares, a redução e geração per capita dos resíduos domiciliares, a qualidade da coleta dos resíduos domiciliares, a sustentabilidade econômica e financeira, a destinação final ambientalmente adequada. 0 município tem uma cobertura de $100 \%$ do sistema de coleta dos resíduos sólidos domiciliares na área urbana. Nos resíduos domiciliares tem-se por volta de $59 \%$ de material orgânico, 35\% material reciclável seco e $6 \%$ de rejeito, sendo os principais resíduos secos domiciliares os papéis, vidros e plásticos. A coleta seletiva do lixo é realizada por empresa terceirizada, abrangendo cem por cento do perímetro urbano, alternando-se as coletas de lixo seco e orgânico (Rio Grande do Sul, 2014). Neste município existem seis associações de recicladores de lixo, sendo cinco localizadas no perímetro urbano, responsável pela reciclagem de lixo seco, e uma localizada no aterro sanitário, reciclando lixo orgânico. Nestas associações trabalham em torno de 89 recicladores.

A reciclagem dos resíduos sólidos urbanos: a opinião dos recicladores de lixo das associações de recicladores do município

Os dados da pesquisa exploratória permitiram identificar e descrever os principais problemas enfrentados pelas associações de recicladores de lixo, conforme descrito a seguir:

1) Separação inadequada do lixo orgânico e do seco: segundo o Entrevistado 3: "há muita falta de conscientização por parte da sociedade, se houvesse uma separação mais adequada seria muito mais rápido". O entrevistado declara ainda que: "vem até lixo hospitalar para cá, seringas de insulinas, sondas [...]. É difícil não se acidentar, não consigo trabalhar com luvas, pois tenho alergia e já me acostumei a trabalhar sem luva, mas sei que é perigoso". 0 Entrevistado 5 afirma que: "o nosso problema é que vem muito lixo orgânico misturado com o seco [...] vem restos de comida, papel higiênico, seringas, frascos de soro, lâmpadas".

2) Falta de infraestrutura e de recursos: das três associações pesquisadas duas ressaltaram que tinham problemas com relação ao tamanho do pavilhão. Ressalta-se, ainda que uma das associações possui uma máquina sem uso em virtude de um acidente com um associado e o equipamento não foi mais operado. 0 
entrevistado 1 aponta que: "pra nós o mais difícil é que o pavilhão é apertado, pois o rejeito acaba sendo estocado até o dia da coleta". Para o entrevistado 4 "se o material chegasse aqui dentro do pavilhão, mas como temos um problema de estrutura recebemos o material fora do pavilhão; [...] muitas vezes não tem como recolher para dentro por causa da chuva, fica difícil".

3) Segurança e falta de EPI: Entrevistado 1: "hoje um dos maiores problemas é em relação aos EPI, este ano já tivemos dois acidentes por falta deles [...] temos muitas vezes que procurar o EPI no lixo para poder utilizar". Entrevistado 2 também diz que: "o que nos causa problema é a falta de EPI, não temos como comprar, temos que procurar aqui mesmo e achar para poder usar".

4) Discriminação da Própria profissão de recicladores: o entrevistado 5 afirma que: "há discriminação por trabalharmos sem carteira assinada e com lixo". 0 entrevistado $2 \mathrm{diz}$ "acredito que a sociedade nos rejeita, pois se for numa loja e disser que é catador não dão muita bola pragente".

Quando abordados sobre possíveis melhorias para os problemas citados a grande maioria sugeriu melhoria na forma como o lixo chega nas associações e nas condições de trabalho. Com relação a primeira, o Entrevistado 2 assim se manifestou que: "houvesse uma maior conscientização da população em relação a separação dos resíduos, pois quanto mais separado o lixo chegar até nós fica melhor a reciclagem". Segundo ele, "no momento que poderíamos estar reciclando e separando o material que podemos vender, estamos fazendo separação do lixo orgânico que acaba vindo junto e tem que ser mandado para o aterro sanitário". O Entrevistado $4 \mathrm{diz}$ que: "deveria melhorar a separação que a população faz, pois quando estamos sem luvas podemos nos cortar". Em relação as melhorias nas condições de trabalho os entrevistados mencionaram necessidade de EPI e treinamento no manuseio de máquinas, conforme relata o Entrevistado 4: "A gente que trabalha aqui deveria ter mais valor e ter o direito de ter um EPI para usar". Para o Entrevistado 3: "se a prefeitura ajudasse mais contribuindo com esses equipamentos seria muito benéfico"; 0 Entrevistado 1 declarou que "se tivesse um treinamento adequado $e$ se o maquinário parado tivesse operando o trabalho seria melhor, ou renderia mais".

\section{A reciclagem dos resíduos sólidos urbanos: a opinião de expert da área}

Os dados obtidos a partir da entrevista com a assistente social e expert do setor, também apontou problemas quanto à segurança dos recicladores, que não usam equipamentos de proteção individual e ao descarte incorreto dos materiais secos e orgânicos. Foi solicitado que a entrevistada falasse sobre a questão ambiental referente aos resíduos sólidos urbanos. Ela assim se manifestou: "Antes trabalhávamos a questão da importância da reciclagem nas escolas e nós podíamos perceber que através das crianças podíamos atingir as famílias [...] quando você consegue trabalhar com a criança lá na escola a criança cobra excessivamente até uma certa idade, por exemplo até o $8^{\circ}$ $e 9^{\circ}$ ano do ensino fundamental. Tudo que a professora ensina vira regra, dessa maneira a criança multiplica esta informação da separação correta do lixo em qualquer lugar que ela for. Então acredito que essa foi uma forma interessante que tivemos de trabalhar a reciclagem". Quando perguntada sobre os principais problemas que existem nas associações de recicladores a expert declarou que há grande dificuldade do lado emocional, questões familiares e sociais, e quando eles estão financeiramente melhor há menos conflitos. Ela fala que teve épocas que os recicladores ganhavam em torno de $\mathrm{R} \$ 200$ a $\mathrm{R} \$ 300$ por mês e isso gerava um problema no contexto familiar. Em outras épocas 
tivemos muitos recicladores que se prostituíam para ter uma renda a mais e ainda, os trabalhadores também não queriam mandar os filhos para a escola, pois queriam incentivá-los a trabalhar junto, hoje já não acontece mais isso.

Eu acho que na questão da reciclagem ou separação ainda temos um grande problema, pois ainda vem muito material hospitalar não direto do hospital, pois sabemos que os hospitais são muito regrados com relação a isso, mas ainda aparece muito material deste tipo eu quero acreditar que por descuido acabou indo para lixo seco. [...] Outra questão que incomoda muito os recicladores são animais mortos jogados no lixo seco, quando vemos este tipo de situação quero acreditar que a pessoa não fez proposital, foi sem querer porque eu fico pensando se aquela pessoa que teve um animal morto na sua casa colocou o lixo na rua ela deve ter pensado isso vai para o aterro sanitário vai ser enterrado se ela conscientemente sabe que vai para um pavilhão de separação acredito que não faria isso.

Perguntou-se também à expert, que estratégias implementaria para melhorar a eficiência do trabalho nas associações de recicladores, caso fosse uma gestora: "Eu acho que tem que ser uma campanha bem-feita na televisão, no rádio que mostre a realidade para onde vai o lixo. Outra é em relação a fiscalização e a cobrança nas empresas que deveriam recolher esse tipo de material. Por exemplo, lâmpadas a que vendeu tem obrigação de recolher". Ela ainda acredita que a fiscalização deveria ser feita pela Prefeitura, a partir da colaboração e denúncia dos consumidores. Com relação à falta de EPI: "uma técnica de segurança do trabalho da Prefeitura foi em todos os pavilhões, conversou com os recicladores [...] ela fez uma listagem e colocou botina, avental, luva, protetor auricular, máscara e óculos para eles comprarem e usarem, botina todos usam, avental e luva alguns, mas a máscara ninguém usa". Perguntouse se a associação não poderia adquirir estes equipamentos, em especial as luvas, já que muitos acabam se ferindo no momento da separação. Segundo ela, os recicladores administram o próprio dinheiro, sendo que recebem proporcional a quantidade separada de resíduos, mas as despesas do pavilhão são divididas igualmente, indiferente se ganharam mais ou menos.

\section{Pesquisa com a população sobre os resíduos sólidos urbanos gerados nas residências do município}

A partir dos resultados da etapa qualitativa, percebeu-se que uma parcela significativa dos problemas relacionados à gestão dos resíduos sólidos urbanos do município pode ter relação direta com a forma com que os mesmos são descartados pela população. Realizou-se então, uma segunda etapa da pesquisa, que se propôs a investigar o nível de conhecimento dos moradores do município sobre aspectos ligados a gestão dos resíduos sólidos urbanos, seus comportamentos em relação ao lixo gerado em suas residências e os procedimentos adotados para a separação e destinação destes materiais.

Os dados da pesquisa possibilitaram traçar o perfil sócio demográfico dos participantes da pesquisa. Verificou-se que $57 \%$ dos respondentes são do sexo feminino, mais de $80 \%$ identificam-se como sendo de cor branca, e a maioria deles tem entre 18 e 30 anos de idade (51,95\%). Com relação a escolaridade, 54\% afirmaram possuir graduação ou pós-graduação completa, $38 \%$ possuem o ensino médio e apenas $8 \%$ o ensino fundamental.

As respostas relativas às profissões desempenhadas pelos respondentes foram muito variadas, compreendendo empregados dos mais diversos ramos de atuação, além de pessoas aposentadas, donas de casa e estudantes. Dentre as profissões mais citadas estão as ligadas à área administrativa, vendedor e professor. 
Com relação ao local de residência dos respondentes, um total de 44 bairros do município foram citados, o que demonstra um bom alcance da pesquisa. Com relação ao número de pessoas que moram em cada residência, a maioria é habitada por três moradores (31\%), seguido pela opção de dois moradores (30\%) e por quatro moradores (21\%). 0 percentual de residências com cinco moradores ou mais alcançou 10\% dos entrevistados e a apenas 8\% afirmam morar sozinhos.

Em relação às questões relativas ao conhecimento da população sobre o destino dos resíduos sólidos urbanos da cidade, cabe uma observação: no questionário, foi denominado apenas "lixo" para evitar confusão dos termos junto aos respondentes. Quando questionados sobre o que acontecia com o lixo após sair das residências, 21,02\% acredita que todo o lixo vai para a reciclagem, porém, cabe mencionar que as associações de recicladores do município recebem (ou deveriam receber) apenas os resíduos secos, devendo os orgânicos serem destinados ao aterro sanitário. Quase 31\% não estão certos sobre o local, mas acreditam que o lixo recolhido é descartado em local adequado.

Quanto à separação dos resíduos secos e orgânicos nas residências, quase a totalidade dos respondentes informou realizá-la. 94\% informaram sim para o orgânico e 96,1\% para o seco, porém, quando questionados se sabem diferenciar o lixo seco e do orgânico quase a metade deles afirmou ter dúvidas a respeito (Figura 1).

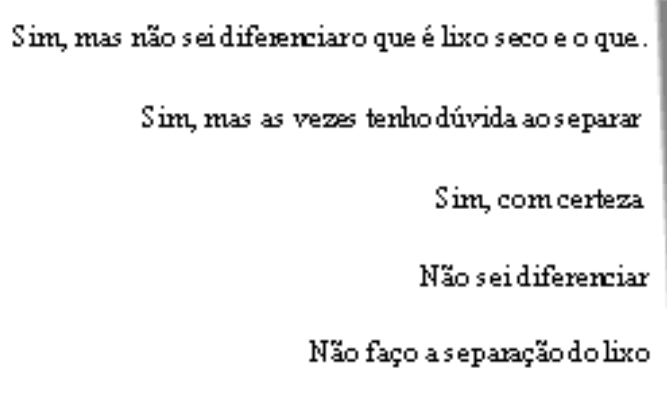

Figura 1. Diferença entre os lixos seco e orgânico.
Outra questão da pesquisa listava diferentes tipos de materiais, incluindo lixo eletrônico, para que os respondentes fizessem a classificação. Percebe-se que de fato há confusão dos respondentes na hora do descarte, pois alguns materiais tiveram uma taxa alta de erro (Tabela 1).

Aqui se destacam os altos percentuais relativos a materiais que oferecem riscos mais graves ao meio ambiente, tais como pilhas, fontes e baterias de celular, lâmpadas e outros materiais eletrônicos, que deveriam passar por um processo de logística reversa das próprias fábricas e muitas vezes acabam indo parar nas associações de recicladores, como fora relatado por eles nas entrevistas, ou descartados em aterros sanitários, na rua ou em terrenos baldios como muitas vezes se vê na mídia. Também houve confusão em itens que oferecem risco imediato à saúde pública e que podem causar contaminações, tais como absorventes e 
preservativos, seringas e outros materiais hospitalares. Estes produtos também foram mencionados pelos recicladores nas entrevistas como causadores de problema e de acidentes por serem descartados erroneamente no lixo seco. Até mesmo o papel é confundido com lixo orgânico por uma pequena parcela dos respondentes, e apenas a garrafa pet obteve $100 \%$ das respostas corretas. Outro dado que chama a atenção diz respeito ao descarte de roupas e sapatos. Numa sociedade em que existem tantas pessoas desprovidas e em situação de vulnerabilidade grave, quase $25 \%$ dos respondentes afirmou não saber o que fazer quando precisa descartar uma roupa ou sapato. Acreditase que dentro deste percentual possa haver uma parcela significativa que ainda apresente condições de uso.

Tabela 1. Classificação de diferentes materiais na percepção dos entrevistados.

\begin{tabular}{|c|c|c|c|c|c|c|}
\hline Diferentes materiais & Seco & Orgânico & Eletrônico & $\begin{array}{l}\text { Não sabe } \\
\text { informar }\end{array}$ & $\begin{array}{l}\text { Opção } \\
\text { correta }\end{array}$ & $\begin{array}{c}\% \text { de erro } \\
\text { ou } \\
\text { desconhe- } \\
\text { cimento }\end{array}$ \\
\hline Papel & $93,69 \%$ & $5,71 \%$ & $0,30 \%$ & $0,30 \%$ & Seco & $6,31 \%$ \\
\hline Televisão & $6,91 \%$ & $0,60 \%$ & $92,19 \%$ & $0,30 \%$ & Eletrônico & $7,81 \%$ \\
\hline Plástico & $99,10 \%$ & & & $0,90 \%$ & Seco & $0,90 \%$ \\
\hline Garrafa PET & $100,00 \%$ & & & & Seco & \\
\hline Roupas e Sapatos & $59,46 \%$ & $14,41 \%$ & $1,20 \%$ & $24,92 \%$ & & \\
\hline Computadores usados & $6,31 \%$ & $0,60 \%$ & $91,89 \%$ & $1,20 \%$ & Eletrônico & $8,11 \%$ \\
\hline Guardanapo de boca usado & $15,92 \%$ & $83,48 \%$ & & $0,60 \%$ & Orgânico & $16,52 \%$ \\
\hline Potes de margarina e iogurte & $87,09 \%$ & $11,41 \%$ & & $1,50 \%$ & Seco & $12,91 \%$ \\
\hline Garrafas de Vidro & $86,49 \%$ & $3,30 \%$ & $1,20 \%$ & $9,01 \%$ & Seco & $13,51 \%$ \\
\hline Lâmpadas & $24,32 \%$ & $4,80 \%$ & $49,25 \%$ & $21,62 \%$ & & \\
\hline Papel higiênico & $11,11 \%$ & $87,69 \%$ & $0,30 \%$ & $0,90 \%$ & Orgânico & $12,31 \%$ \\
\hline Fontes de celular & $6,31 \%$ & $0,90 \%$ & $90,09 \%$ & $2,70 \%$ & Eletrônico & $9,91 \%$ \\
\hline Galhos de árvores & $12,01 \%$ & $72,37 \%$ & $1,20 \%$ & $14,41 \%$ & & \\
\hline Ferro & $62,46 \%$ & $1,20 \%$ & $10,21 \%$ & $26,13 \%$ & Seco & $37,54 \%$ \\
\hline Restos de alimentos & $4,20 \%$ & $95,50 \%$ & & $0,30 \%$ & Orgânico & $4,50 \%$ \\
\hline Baterias de celular & $6,01 \%$ & $1,80 \%$ & $87,69 \%$ & $4,50 \%$ & Eletrônico & $12,31 \%$ \\
\hline Pilhas & $6,61 \%$ & $2,70 \%$ & $81,08 \%$ & $9,61 \%$ & Eletrônico & $18,92 \%$ \\
\hline $\begin{array}{l}\text { Absorventes e preservativos } \\
\text { usados }\end{array}$ & $11,41 \%$ & $81,68 \%$ & $0,90 \%$ & $6,01 \%$ & Orgânico & $18,32 \%$ \\
\hline Eletrodomésticos & $7,51 \%$ & $1,50 \%$ & $87,99 \%$ & $3,00 \%$ & Eletrônico & $12,01 \%$ \\
\hline $\begin{array}{l}\text { Seringas, curativos e outros } \\
\text { materiais hospitalares }\end{array}$ & $15,92 \%$ & $28,23 \%$ & $3,00 \%$ & $52,85 \%$ & & \\
\hline Revistas e jornais & $92,49 \%$ & $6,31 \%$ & $0,30 \%$ & $0,90 \%$ & Seco & $7,51 \%$ \\
\hline
\end{tabular}


Quando questionados sobre o que fazem com o lixo gerado em suas casas, (Tabela 2), pode-se perceber que 95\% dos entrevistados destinam o lixo seco à coleta seletiva. Do lixo orgânico gerado, $85 \%$ destinam à coleta seletiva e $12 \%$ o colocam na horta. Identificou-se que o maior problema está no lixo eletrônico, já que somente $79 \%$ fazem a destinação correta, os demais os colocam no lixo seco, no orgânico, ou ainda, jogam em terrenos baldios, e neste último caso, podem gerar problemas ambientais e criar vetores que podem causar doenças. Destaca-se ainda que uma parte da população desconheça a existência de um aterro sanitário e de associações de recicladores no município (Tabela 4).

Tabela 2. Destino do lixo gerado nas residências.

\begin{tabular}{lccc}
\hline O que é feito com o lixo gerado em sua casa? & Seco & Orgânico & Eletrônico \\
\hline Coloca na horta & & $12,31 \%$ & \\
Destina para a coleta seletiva & $95,50 \%$ & $84,98 \%$ & \\
Joga em terrenos baldios & & & $0,60 \%$ \\
Joga no lixo orgânico & & $1,80 \%$ \\
Joga no lixo seco & & $14,11 \%$ \\
Leva em postos identificados para recolhimento & & $79,28 \%$ \\
Queima & $3,00 \%$ & \\
Separa e comercializa & $0,30 \%$ & \\
\hline
\end{tabular}

Os respondentes também foram perguntados a respeito da destinação final do lixo que é gerado pelo município como um todo, e uma parcela dos respondentes demonstram não ter conhecimento a respeito, sendo que $27,63 \%$ responderam que não sabem informar o que é feito com o lixo seco,
$20,78 \%$ não sabem o que é feito com o orgânico e 33,03\% não sabem o que é feito com o lixo eletrônico (Tabela 3). Os respondentes também foram questionados quanto a responsabilidade da prefeitura a respeito da reciclagem do lixo gerado no município (Figura 2).

Tabela 3. Conhecimento sobre o destino dos resíduos sólidos no município.

\begin{tabular}{lccc}
\hline Você sabe o que é feito com o lixo gerado no município? & Seco & Orgânico & Eletrônico \\
\hline Não sabe informar & $27,63 \%$ & $20,72 \%$ & $33,03 \%$ \\
O lixo é jogado em terrenos baldios & $0,30 \%$ & $0,90 \%$ & \\
O lixo que é recolhido é queimado & & $0,30 \%$ & $0,30 \%$ \\
Vai para as associações de catadores & $61,56 \%$ & $1,80 \%$ & $2,40 \%$ \\
Vai para o aterro sanitário & $5,41 \%$ & $66,97 \%$ & $0,90 \%$ \\
Vai para o lixão & $5,11 \%$ & $9,61 \%$ & \\
Vai para uma empresa de reciclagem especializada & & & $63,36 \%$ \\
\hline
\end{tabular}


Tabela 4. Existem no município associação (ões) de recicladores ou aterro(s) sanitário(s)?

\begin{tabular}{lcc}
\hline & Sim & Não \\
\hline Associações de recicladores & $79,28 \%$ & $20,72 \%$ \\
Aterro Sanitário & $75,38 \%$ & $24,62 \%$ \\
\hline
\end{tabular}
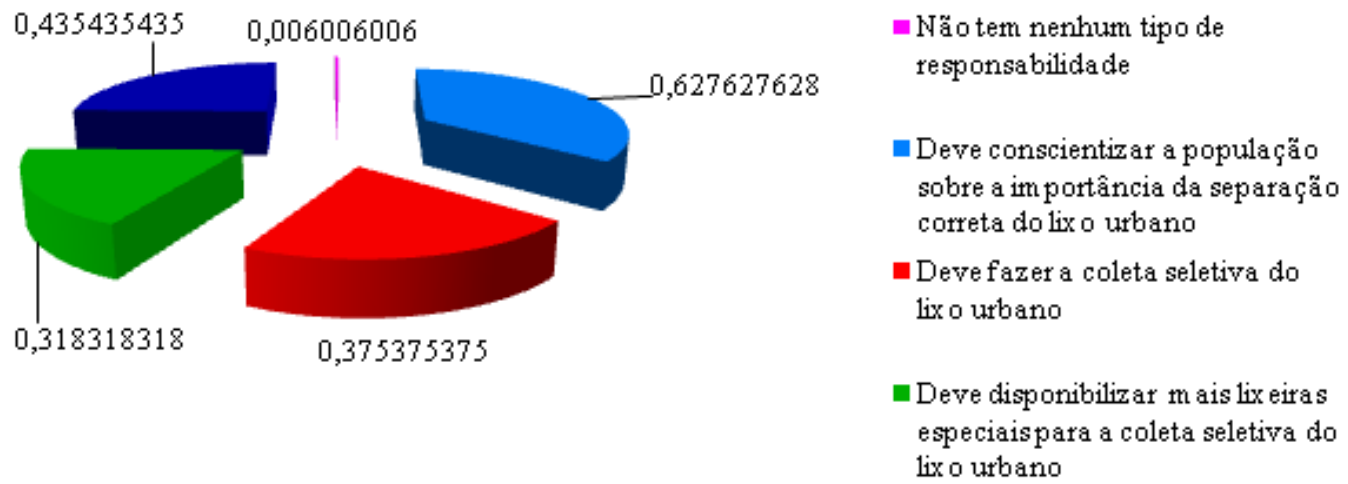

Figura 2. Responsabilidade da Prefeitura Municipal com relação à reciclagem do lixo.

Cabe ressaltar que os respondentes podiam marcar mais de uma resposta nesta opção. Como mostram os dados, a grande maioria acredita que a conscientização da população sobre a importância e a correta separação do lixo urbano. Outra parcela significativa acredita que a prefeitura deve realizar uma fiscalização rigorosa, seguido daqueles que entendem que cabe a prefeitura a realização da coleta e disponibilização de lixeiras especiais. Menos de $1 \%$ dos respondentes não atribui nenhuma responsabilidade à prefeitura.

E ainda, em várias respostas abertas da mesma questão, os pesquisados acreditam que se a prefeitura desenvolvesse uma política pública que tratasse da questão do lixo com foco na separação e na conscientização seria um grande avanço, visto que a maioria das pessoas não possui informações corretas sobre os pontos de recolhimento para determinados tipos de resíduos. Acreditam que a prefeitura deveria ter uma equipe que recolhesse alguns tipos de lixos como móveis, pneus, e muitos outros resíduos descartados incorretamente. Para muitos, a prefeitura deveria fazer muito mais do que é feito nos dias atuais, visto que deveria investir também reciclagem não somente coleta seletiva.

\section{Análise SWOT}

Após as etapas qualitativa e quantitativa, realizou-se uma análise SWOT dos resultados encontrados, com o objetivo de situar os achados em termos de oportunidades e ameaças, pontos fortes e pontos fracos, sintetizando e mapeando estes resultados, para a partir desses propor estratégias de marketing sustentável que possam contribuir para a gestão dos resíduos sólidos urbanos secos no Município de Erechim. 
Tabela 5. Matriz SWOT.

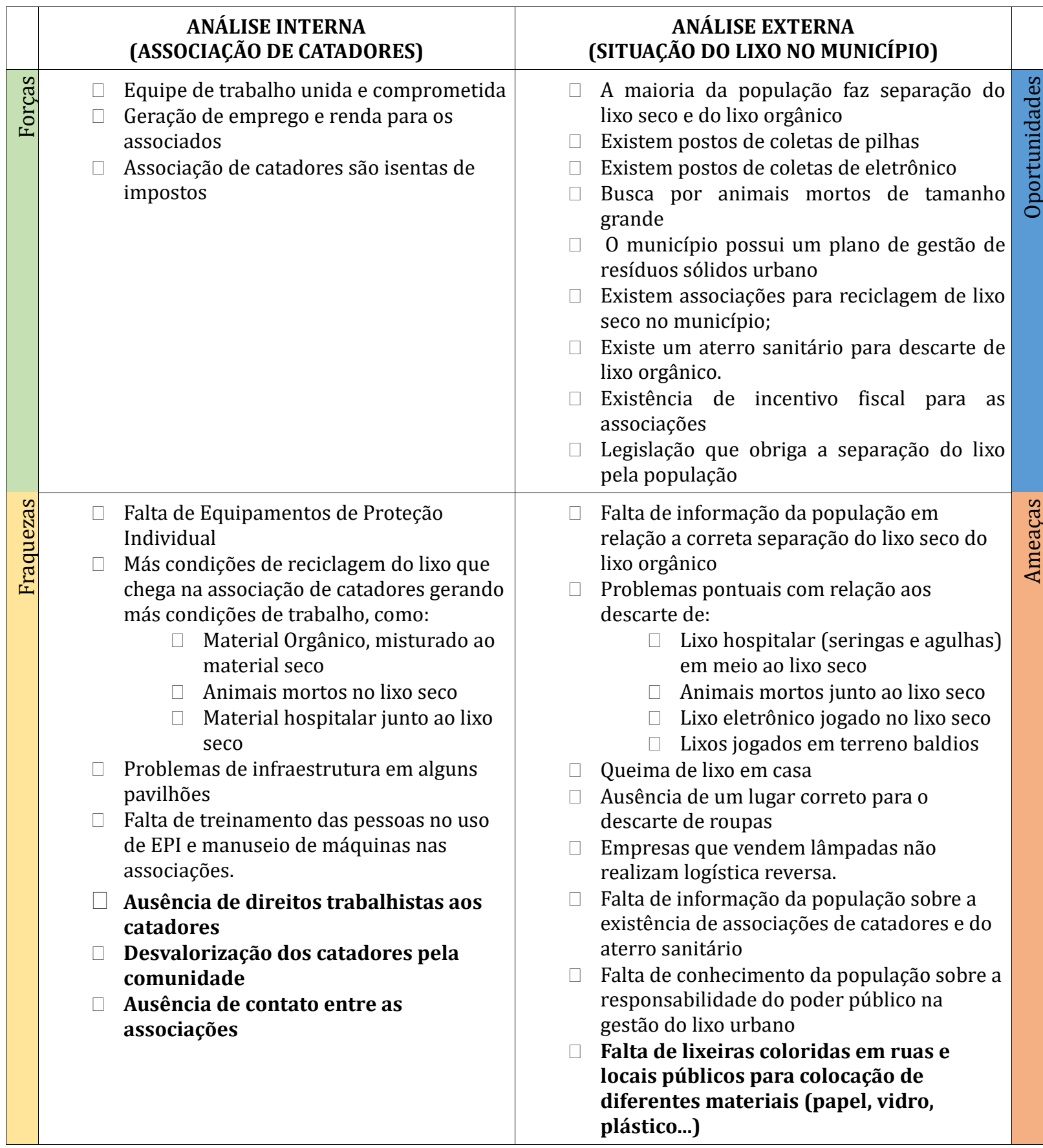

Estratégias de marketing para a melhoria da gestão de resíduos sólidos urbanos

Com relação à melhoria da gestão dos resíduos sólidos, as ações se referem à prevenção, reciclagem, reutilização e transformação (Cortez, 2016). A prevenção é um dever de produtores e consumidores; a reciclagem e reapro- veitamento de embalagens estão diretamente associados ao pós-consumo. Considerando isso, e a partir dos resultados das etapas qualitativa $\mathrm{e}$ quantitativa desta pesquisa, bem como, da matriz SWOT, propõe-se estratégias de marketing sustentável para prevenção, reciclagem, reutilização de resíduos 
sólidos urbanos secos, numa visão ambiental, social e econômica.

Estratégia 1 - Realização de campanhas de conscientização da população em relação a gestão ecoeficiente de resíduos sólidos urbanos secos: segundo dados da pesquisa, identificou que $48,03 \%$ dos pesquisados alegaram separar o lixo, porém têm dúvidas quanto a separação correta dos resíduos sólidos, sejam eles, secos, orgânicos e eletrônicos. Quando solicitou-se aos respondentes que classificassem os resíduos em seco, orgânico e eletrônico, verificou-se que a maioria separa erradamente o material e, exemplo disso, é que mais de $11 \%$ afirmaram jogar potes de margarina e iogurte no lixo orgânico, sendo estes materiais secos que deveriam ir às associações de recicladores; quase $8 \%$ classificou as televisões como lixo seco, quando deveriam ser lixo eletrônico. Neste sentido, percebe-se que existe uma parcela significativa da população que desconhece a destinação correta dos resíduos sólidos urbanos. Assim, sugerese que sejam realizadas campanhas de informação e conscientização da população sobre o destino correto dos resíduos sólidos urbanos, as quais podem ser veiculadas através de propagandas em televisão, marketing direto e em redes sociais. Segundo Shimp (2009), campanhas devem conter uma estratégia publicitária (definição clara de objetivos, elaboração de orçamentos, criação de mensagem cativante, seleção de mídias e veículos), ser implementada e avaliada visando atingir seu objetivo. Zenone e Dias $(2015$, p. 106) lembram "que a estratégia de comunicação deve ser informativa e não persuasiva, conscientizando o consumidor de uma prática consciente". Já Moreira e Okalda (2011) e Silva et al. (2013), apontam que as redes sociais se tornaram uma ferramenta muito forte quando se aborda marketing e comunicação em massa. Para os autores, a migração do consumo para a web, as facilidades dos mecanismos de buscas por melhores produtos, 0 aumento do consumo em tempo real, são tendências irreversíveis que exigem das organizações estratégias de marketing eficientes. Neste sentido, os autores enfatizam que é imperativo gerenciar a comunicação empresarial na "era da busca", exigindo a formulação de estratégias de marketing dirigidas $\mathrm{e}$ sustentáveis.

Estratégia 2 - Criação de postos verdes de coleta: 0 estudo apontou que muitos objetos hospitalares, como seringas, agulhas, sondas, curativos, de uso doméstico, por diabéticos e doentes em tratamento domiciliar, por serem descartados de forma incorreta podem machucar e contaminar os recicladores de lixo. As roupas usadas também não são recicláveis, e, normalmente são lançadas erroneamente no lixo seco, ficando totalmente inutilizadas para o uso. Da mesma forma outros tipos de resíduos, como pilhas e baterias, pequenos aparelhos eletrônicos e celulares, quando não mais utilizados, são colocados de forma incorreta em lixo seco. Neste sentido, sugere-se a intensificação de campanhas de doação de roupas e agasalhos, em todas as épocas do ano e não apenas próximos ao inverno, e a identificação de postos de coleta para que estas possam ser doadas. Com relação as pilhas, baterias e eletrônicos, bem como, materiais hospitalares, sugere-se a instalação de ecocontainers em diferentes pontos da cidade, para coleta e descarte correto destes materiais. Estes ecocontainers podem ser instalados em ruas, escolas, órgãos públicos, empresas do setor privado, postos de gasolina e demais de grande circulação, sendo posteriormente retirados e descartados de maneira adequada, já que segundo Machado (2015), é função do sistema de coleta e transporte buscar os resíduos nos locais onde são gerados ou entregues voluntariamente e dar a destinação correta. De modo a oportunizar um caráter mais inovador à proposta, poderiam também ser criados pontos verdes de coleta ou ecopontos, 
entendidos como "local ecologicamente correto para o descarte de resíduos", conforme denominados nos trabalhos de Marcucci (2017) e Cortez (2016). No que se refere a estes pontos verdes de coleta, Cortez (2016) em seu estudo sobre o sistema que integra o Gerenciamento de Resíduos da Catalunha, denominou-os como sendo estruturas/locais para depósito e recuperação dos resíduos que não podem ser depositados nos conteiners dispostos nas ruas, e que posteriormente são removidos para estações de tratamento mais adequadas.

Estratégia 3 - Implantação da Logística Reversa: A logística reversa pode ser entendida como um "instrumento de desenvolvimento econômico e social, caracterizado por um conjunto de ações, procedimentos e meios destinados a viabilizar a coleta e a restituição dos resíduos sólidos ao setor empresarial, para reaproveitamento, em seu ciclo ou em outros ciclos produtivos, ou outra destinação final ambientalmente adequada" (Brasil, 2014). Segundo Ballou (1993), a preocupação com o meio ambiente cresceu junto com a população e com a industrialização, tendo como uma das suas grandes preocupações a reciclagem dos resíduos sólidos. Porém, enquanto o mundo possui sofisticados canais para as matérias-primas ou produtos finais das empresas, pouca atenção tem sido dada à reutilização destes materiais de produção. Ainda segundo o autor: "é geralmente mais barato usar matérias primas virgens do que material reciclado, em parte pelo pouco desenvolvimento dos canais de retorno, que ainda são menos eficientes do que os canais de distribuição de produtos" (Ballou, 1993, p. 348). Segundo Ziviani et al. (2014), graças a crescente conscientização ambiental dos consumidores, ações de logística reversa também revertem em benefícios econômicos para as empresas, e podem ser vistas como ferramenta de diferenciação destas perante a concorrência, resultando em ganho de vantagem competitiva. Neste sentido, sugere-se ação junto aos fornecedores de materiais eletrônicos, pneus e outros materiais de possível retorno buscando viabilizar o processo reverso destes materiais pós-consumo e a sua transformação, aliado a ações contínuas de conscientização. Em paralelo, também são propostas ações de conscientização da população a respeito dos resíduos que são passíveis de retorno aos fornecedores, pois a pesquisa realizada por Carvalho (2017) apontou que $21,68 \%$ dos entrevistados não sabem o que fazer com as lâmpadas, por exemplo.

Estratégia 4 - Melhoria da segurança do trabalho com a aquisição de equipamento de proteção individual EPI: Sugere-se que a Prefeitura Municipal se responsabilize pela aquisição de suas luvas de proteção. Os custos contabilizam que: existem 89 recicladores distribuídos nas 6 associações de recicladores do município de estudo; que são necessárias 178 luvas/mês, o valor da luva é de $\mathrm{R} \$ 5,95$, o que geraria um total de $1.059,00 /$ mês. De acordo com uma técnica em segurança do trabalho, citada pela expert em sua entrevista, existe também a necessidade de uso de luvas anticortes, revestida com poliuretano, oferecendo uma maior segurança, e com vida útil de um ano. Estimou-se que as associações precisam de 86 luvas/ano, num valor de $R \$ 39,00$ cada, gerando um investimento de R\$3.551.00/ano. Além destes equipamentos, há também a necessidade de botinas e aventais. Segundo dados da pesquisa, a expert corrobora com esta proposta quando diz: "as associações já fizeram reivindicações à Prefeitura Municipal, através do Secretário Municipal de Meio Ambiente. [...] considerando o gasto mensal, é dinheiro para eles (da associação). [...] mas agora eu me pergunto, eles são pessoas de baixa renda que estão fazendo um trabalho fundamental para 0 município, será que a Prefeitura não poderia repassar esse valor por mês para manter uma qualidade de vida de saúde para essas pessoas?". 
Estratégia 5 - Ações

de marketing de relacionamento entre as associações de recicladores e a sociedade: De acordo com Palmatier (2008), o marketing de relacionamento e a sua gestão encontram-se no centro da estratégia de marketing há 20 anos. Para Morgan e Hunt (1994), o alicerce do marketing de relacionamento está no entendimento de que as ações de benefício mútuo são muito mais interessantes para as organizações do que o antagonismo, e que, portanto, este tipo de ação deve ser disseminada pelos mais diversos grupos de interesse de uma organização. As entrevistas apontaram que os recicladores se sentem desvalorizados pela comunidade, e em alguns casos, discriminados em função da sua ocupação. No mesmo sentido, Carvalho (2017), em sua pesquisa com a comunidade do município de estudo constatou que aproximadamente 20\% dos respondentes se quer sabe da existência destas associações. Neste sentido, sugere-se a criação de elos de relacionamento com a comunidade, em ações que destaquem a importância do trabalho dos recicladores e a responsabilidade socioambiental das associações. Isso poderia ser feito através de visitas da população aos pavilhões de reciclagem; inserção dos recicladores nas atividades que são promovidas na semana do meio ambiente; eventos nas escolas, realização de oficinas em conjunto com os recicladores, demonstrando o descarte correto dos materiais; ações de visitação das escolas aos pavilhões de reciclagem para que os alunos possam entender a realidade vivenciada por eles e os danos que o descarte incorreto pode causar ao meio ambiente. Kotler e Keller (2013) apontam que um dos objetivos de marketing é justamente o desenvolvimento de um relacionamento duradouro com todos os stakeholders para satisfação mútua com seus componentes-chave, visando a conquistar ou a manter negócios.

\section{Considerações finais}

A realização da presente pesquisa possibilitou conhecer alguns dos principais problemas relacionados à gestão dos resíduos sólidos urbanos do Município de Erechim, no Alto Uruguai Gaúcho, com base na visão daqueles que atuam diretamente com a reciclagem, como os recicladores das associações investigadas e uma profissional do setor. Os principais problemas relatados foram: a falta de informação e conscientização da população sobre a separação do lixo urbano, infraestrutura deficiente em algumas associações, falta de segurança relacionada à ausência de EPIs, e a discriminação sofrida pelos recicladores por estarem trabalhando com lixo.

Constata-se que a gestão dos resíduos sólidos urbanos é um tema importante ligado ao marketing sustentável, que tem como filosofia definir estratégias com foco no tripé social, ambiental e econômico. Em consonância com o marketing sustentável, propôs-se algumas estratégias de marketing no sentido de informar e conscientizar a população em relação a reciclagem do lixo, através de propagandas institucionais, a aquisição de EPI's; criação de postos de coleta de materiais hospitalares, roupas; incentivo a logística reversa de materiais eletrônicos e afins, e ainda, ações de marketing de relacionamento que melhorem a visão da sociedade sobre o papel exercido pelos recicladores.

Como implicações gerenciais oportunizadas por esta pesquisa, destaca-se a possibilidade das ações propostas melhorarem a atuação dos recicladores dentro das associações. Como implicações acadêmicas, apesar do seu caráter exploratório, que levou em conta apenas a perspectiva de um público específico (no caso, os recicladores e expert), ressalta-se que a pesquisa possibilitou insigts interessantes que possibilitam avançar na pesquisa futuramente. 
A partir deste estudo pode-se concluir que a gestão adequada dos resíduos sólidos é o objetivo maior dos planos nacional, estadual e municipal, e envolve aspectos ligados à educação ambiental, à coleta seletiva, ao estímulo à comercialização de materiais recicláveis, à compostagem, à inclusão de recicladores e à adoção de sistema ambientalmente adequado para a disposição final de rejeitos. Destaca-se que fatores socioculturais, econômicos, legais, políticos e ambientais, bem como os recursos disponíveis são os principais problemas que afetam a gestão de resíduos sólidos urbanos. É por isso que a adoção de qualquer nova tecnologia ou de estratégias de marketing devem levar em conta o efeito e a influência sobre o sociocultural e a economia da comunidade.

Neste sentido, estudos futuros podem tratar especificamente de cada etapa prevista na PNRU (Brasil, 2011) e seus impactos. Sugere-se, ainda, a realização de levantamentos com diferentes públicos de interesse, dentre os quais a população (domicílios, industriais, comerciais, construção civil, estudantes), enquanto responsáveis pela geração do lixo urbano, e os órgãos públicos na condição de responsáveis pela sua gestão. Acredita-se que a análise conjunta destes diferentes pontos de vista possa contribuir para a implantação de estratégias de marketing sustentável e formulação de planos de ação mais detalhados que gerem resultados mais expressivos em prol do planeta e da qualidade de vida das pessoas.

\section{Conflitos de interesse}

Os autores declaram não haver conflitos de interesse.

\section{Referências}

AMA-Americam Marketing Association. Definição de marketing. 2013. Disponível em: <http://www.marketingpower.com/
AboutAMA/Pages/DefinitionofMarketing.asp $\mathrm{x}>$. Acesso em: 06 abr. 2017.

Ambrósio, V. Planos de marketing: passo a passo. São Paulo: Pearson Prentice Hall, 2007.

Assumpção, L. F. J. Sistema de gestão ambiental: manual prático para a implementação de SGA e Certificação ISO 14.001. 3. ed. Curitiba: Juruá, 2011.

Baldassarre, F.; Campo, R. Sustainability as a marketing tool: To be or to appear to be? Business Horizons, v. 59 n. 4, p. 421-429, 2016. https://doi.org/10.1016/j.bushor. 2016.03.005

Ballou, R. H. Logística empresarial. São Paulo: Atlas, 1993.

Bartholomeu, D. B.; Caixeta-Filho, J. V. (Org.). Logística ambiental de resíduos sólidos. São Paulo: Atlas, 2011.

Brasil. Ministério do Meio Ambiente. Plano Nacional de Resíduos Urbanos. 2011. Disponível em: <http://www.mma.gov.br/ estruturas/253/_publicacao/253_publicacao 02022012041757.pdf>. Acesso em: 12 mar. 2017.

Brasil. Ministério do Meio Ambiente. Gestão Integrada dos Resíduos Sólidos. 2014. Disponível em: <http://www.mma.gov.br/ responsabilidade-socioambiental/a3p/eixostematicos/gestão-adequada-dos-resíduos/ item/9338>. Acesso em: 27 fev. 2017.

Brasil. Lei no 8.666, de 21 de junho de 1993. Regulamenta o art. 37 , inciso XXI, da Constituição Federal, institui normas para licitações e contratos da Administração Pública e dá outras providências. Disponível em: <http://www.planalto.gov.br/ccivil_03/ LEIS/L8666cons.htm>. Acesso em: 20 jun. 2017.

Brasil. Lei no 12.305, de 2 de agosto de 2010. Institui a Política Nacional de Resíduos Sólidos; altera a Lei no 9.605, de 12 de fevereiro de 1998; e dá outras providências. Disponível em: <http://www.planalto.gov .br/ccivil_03/_ato2007-2010/2010/lei/ 112305.htm>. Acesso em: 20 jun. 2017.

Carvalho, M.S. Estratégias de marketing para a gestão dos resíduos sólidos urbanos no Município de Erechim/RS. Erechim: Instituto Federal de Educação, Ciência e Tecnologia do Rio Grande do Sul, 2017. (Trabalho de Conclusão de Curso). 
Cortez, A. T.C. Aplicação de métodos e técnicas sustentáveis na gestão de resíduos sólidos. GeoGraphos, v. 7, n. 87, art. 4, 27 p., 2016. Disponível em: <https://web.ua.es/es/ revista-geographos-giecryal/documentos/ pydes-4-caceres.pdf>. Acesso em: $20 \mathrm{fev}$. 2017.

Enoki, P. A.; Adum, S. H. N.; Ferreira, M. Z.; Aureliano, C. A.; Vealdevino, S. L. Estratégias de marketing verde na percepção de compra dos consumidores na grande São Paulo. Anais do III Encontro de Marketing da ANPAD, Curitiba, 2008. Disponível em <http://www.anpad.org.br/admin/pdf/EMA 159.pdf>. Acesso em: 20 fev. 2017.

Erechim. Plano Municipal de Resíduos Sólidos do Município. 2017. Disponível em: <http://www.pmerechim.rs.gov.br/uploads/f iles/PLANO DE SANEAMENTO DE RESÍDUOS 1ํ REVISÃO (1).pdf>. Acesso em: 18 nov. 2017.

Ezeah, C.; Roberts C. L. Analysis of barriers and success factors affecting the adoption of sustainable management of municipal solid waste in Nigeria. Journal of Environmental Management, $\quad$ v. 103, p.9-14, 2012. https://doi.org/10.1016/j.jenvman.2012.02. 027

Godecke, M. V.; Naime, R. H.; Figueiredo, J. A. S. O consumismo e a geração de resíduos sólidos no Brasil. Revista Eletrônica em Gestão, Educação e Tecnologia Ambiental, v. 8, n. 8, p. 1700-1712, 2012. https://doi.org/10.5902/223611706380

Gouveia, N. Resíduos sólidos urbanos: impactos socioambientais e perspectiva de manejo sustentável com inclusão social. Ciência \& Saúde Coletiva, v. 17, n. 6, p. 15031510, 2012. https://doi.org/10.1590/S141381232012000600014

Gracioso, F. Marketing estratégico: planejamento estratégico orientado para o mercado. 6. ed. São Paulo: Atlas, 2012.

Hussein, I. A.; Mona, S. M. Mansour solid waste issue: Sources, composition, disposal, recycling, and valorization. Egyptian Journal of Petroleum, v. 27, n. 4, p. 1275-1290, 2018. https://doi.org/10.1016/j.ejpe.2018.07.003

IBGE - Instituto Brasileiro de Geografia e Estatística. Sinopse de Censo Demográfico 2010. Rio Grande do Sul. 2010. Disponível em: <https://censo2010.ibge.gov.br/sinopse /index.php?dados $=29 \& u f=43>$. Acesso em: 05 maio 2017.

Jacobi, P. R. J.; Besen, G. R. Gestão de resíduos sólidos em São Paulo: desafios da sustentabilidade. Estudos Avançados, v. 25, n. 71, p. 135-158, 2011. https://doi.org/ 10.1590/S0103-40142011000100010

Kotler, P.; Kartajaya, H.; Setiawan, I. Marketing 3.0: as forças que estão definindo o novo marketing centrado no ser humano. Rio de Janeiro: Elsevier, 2010.

Kotler, P.; Keller, K. L. Administração de marketing. 14. ed. São Paulo: Pearson Education, 2013.

Kumar, V.; Rahman, Z; Kazmi, A. A.; Goyal, P. Evolution of sustainability as marketing strategy: Beginning of new era. Procedia Social and Behavioral Sciences, v. 37, p. 482-489, 2012. https://doi.org/10.1016/ j.sbspro.2012.03.313

Li, H.; Nitivattananon, V.; Li, P. Developing a sustainability assessment model to analyze China's municipal solid waste management enhancement strategy. Sustainability, v. 7, n. 2 , p. $1116-1141$, 2015. https://doi.org/ $10.3390 /$ su7021116

Liyala, C. M. Modernizing solid waste management at municipal level: Institutional arrangements in urban centers of East Africa, Environmental Policy Series. The Netherlands: Wageningen University, 2011. (PhD Thesis).

Machado, G. B. Sistemas de coleta e transporte de resíduos sólidos. 2015. Disponível em: <http://www.portalresiduos solidos.com/sistemas-de-coleta-e-transpor te-de-residuos-solidos/>. Acesso em: $21 \mathrm{fev}$. 2017.

Malhotra, N. Pesquisa de marketing: uma orientação aplicada. Porto Alegre: Bookman, 2012.

Marcucci, J. C. Limites e Possibilidade para o gerenciamento de resíduos sólidos urbanos: o exemplo dos ecopontos no Município de Rio Claro. São Paulo: Universidade Estadual Paulista, 2017. (Dissertação de Mestrado).

Moreira, E. S.; Okada, L. Estratégias de marketing digital na Era da Busca. Revista Brasileira de Marketing, v. 10, n. 1, p. 46-72, 2011. https://doi.org/10.5585/remark.v10 i1.2199 
Morgan, R. M.; Hunt, S. The commitment-trust theory of relationship marketing. Journal of Marketing, v. 58, $\quad$ n. 3, p. 20-38, 1994. https://doi.org/10.2307/1252308

Palmatier, R.W. Relationship marketing: Relevant knowledge series. Cambridge: Marketing Science Institute, 2008.

Peltola, T.; Aarikka-Stenroos, L.; Viana, E.; Mäkinen, S. Value capture in business ecosystems for municipal solid waste management: Comparison between two local environments. Journal of Cleaner Production, v. 137, n. 1, p. 1270-1279, 2016. https://doi.org/10.1016/j.jclepro.2016.07.168

Pomering, A. Marketing for sustainability: Extending the conceptualisation of the marketing mix to drive value for individuals and society at large. Australasian Marketing Journal, v. 25, p. 157-165, 2017. https://doi.org/10.1016/j.ausmj.2017.04.011

Queiroz, N. T.; Vieira, E. T. V. Gestão de resíduos sólidos na zona urbana do Município de Varzelândia, Minas Gerais, Brasil: um olhar pela via da gestão municipal e impressões da população. Revista Brasileira de Gestão Ambiental e Sustentabilidade, v. 5, n. 9, p. 141-156, 2018. https://doi.org/10.21438/rbgas.050909

Rio Grande do Sul. Plano estadual de resíduos sólidos do Rio Grande do Sul 2015-2034. 2014. Disponível em: <http://www.pers.rs.gov.br/arquivos/ENGBSEMA-PERS-RS-40-Final-rev01.pdf>. Acesso em: 02 maio 2017.

Rodrigues, A. P.; Fernandes, M. I.; Rodrigues, M. F. F.; Bortoluzzi, S. C.; Gouvea da Costa, S. E.; Pinheiro de Lima, E. Developing criteria for performance assessment in municipal solid waste management. Journal of Cleaner Production, v. 186, p.748-757, 2018. https://doi.org/10.1016/j.jclepro.2018.03.067

Saffer, M.; Izawa, M. K.; Duarte, G. A. A.; Javier,

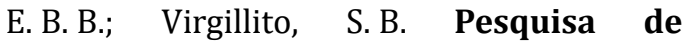

marketing: uma abordagem quantitativa e qualitativa. São Paulo: Saraiva, 2010.

Seadon, J. K. Sustainable waste management systems. Journal of Cleaner Production, v. 18, n. 16/17, p. 1639-1651, 2010. https://doi.org/10.1016/j.jclepro.2010.07.009

Silva, E. N.; Santos, T. J.; Souza, R.; Pereira, N. C.; Mariano, A. M. Uso de redes sociais no marketing empresarial: vantagens e desvantagens da publicidade na rede. Anais do Congresso Internacional de Administração - Gestão Estratégica: Criatividade e Interatividade, Ponta Grossa, 2013.

Silva Filho, C. R. V. D.; Soller, F. D. Gestão de resíduos sólidos: o que diz a lei. São Paulo: Trevisan Editora Universitária, 2012.

Shimp, T. A. Comunicação integrada de marketing: propaganda e promoção. 7. ed. Porto Alegre: Bookmand, 2009.

Stumpf, U. D.; Theis, V.; Schreiber, D. Gestão de resíduos sólidos em empresas melalomecânicas de pequeno porte. Revista de Gestão Ambiental e Sustentabilidade, $\begin{array}{llll}\text { v. } 7, \quad \text { p. } 2, & 230-247, & \end{array}$ https://doi.org/10.5585/geas.v7i2.598

Yin, R. Estudo de caso: metodologia e métodos. 5.ed. Porto Alegre: Bookmann, 2015.

Zenone, L.C. Marketing estratégico e competitividade empresarial: formulando estratégias mercadológicas para organizações de alto desempenho. São Paulo: Novatec, 2007.

Zenone, L. C.; Dias, R. Marketing sustentável: valor social, econômico e mercadológico. São Paulo: Atlas, 2015.

Ziviani, A.; Folgado, R. E.; Tavares, C. Logística reversa: uma estratégia para $o$ ganho de vantagem competitiva, en Contribuciones a la Economía, 2014. Disponível em: <http://www.eumed.net/ ce/2014/4/logistica-reversa.html>. Acesso em: 11 mar. 2018.

Informação da Licença: Este é um artigo Open Access distribuído sob os termos da Licença Creative Commons Attribution, que permite uso irrestrito, distribuição e reprodução em qualquer meio, desde que a obra original seja devidamente citada. 